\title{
Preparation of a dynamic simulation model to support decision making in a shallow lake area
}

\author{
Mónika Varga ${ }^{1}$, Sándor Balogh², Béla Csukás ${ }^{3}$
}

\begin{tabular}{ll}
\hline $\begin{array}{l}\text { I N F O } \\
\text { Received 11 Dec 2014 } \\
\text { Accepted 7 Jan 2015 }\end{array}$ & A B S T R A C T \\
Available on-line 14 Jan 2015 & $\begin{array}{l}\text { This paper focuses on the demonstration of a conceptual framework and a dynamic } \\
\text { simulation based tool, through the example of southern catchment basin of Lake Balaton. } \\
\text { Responsible Editor: M. Herdon } \\
\text { The objective is to support the sustainable and reasonable environmental management by } \\
\text { model based investigation of various scenarios. In the developed hydrological model, the } \\
\text { coherence is given by the compartmentalized dynamic network of water flows and water }\end{array}$ \\
$\begin{array}{l}\text { Keywords: } \\
\text { dynamic simulation model, } \\
\text { decision support, environmental } \\
\text { management, Lake Balaton }\end{array}$ & $\begin{array}{l}\text { area by modeled patches, corresponding to the CORINE land cover database of natural } \\
\text { and human built environment. The complexity of the large scale and long term processes } \\
\text { is managed by evaluating detailed models only for one representative patch from each } \\
\text { class, while the calculation of the similar patches is solved by simple multiplication rules. } \\
\text { According to the first experiences, the developed framework is able to integrate the field } \\
\text { experts' knowledge (data, relations, empirical knowledge, etc.) for the prediction of land } \\
\text { use effects besides different climatic scenarios. It is noted, that continuous extension and } \\
\text { refinement of the model and of the involved data is necessary, especially through more } \\
\text { realistic case studies. }\end{array}$
\end{tabular}

\section{Introduction}

\subsection{Brief overview of the existing methods}

Simulation based water assessment of catchment basins has been solved by sophisticated tools since many decades. Dynamic computational models intend to cover both natural and human-built processes, while complex investigations have to take into consideration the anthropogenic effects. This complexity and the highly multidisciplinary characteristics of problems require the involvement of integrated computer modeling frameworks for the analysis, design and operation of sustainable watershed management. The application of an appropriately identified and validated model, besides its prediction ability, can enhance the understanding of the hidden cause-and-effect relations (Knapen et al., 2013) and it can provide a sound basis for the communication between the experts of different disciplines. Because of the strong need, arisen from both researchers and decision makers, the availability of such modeling systems has been increasing in the last decades.

From the 1970-80's, environmental model based investigations basically focused on site-specific, isolated models (Duckstein et al., 1982, Alley et al., 1986) that are not easily modifiable and flexible enough to extend them for the investigation of processes in another spatial or temporal scale (Zagona, 2001). On that time an overview about complex environmental modeling methods, involving hydrological modules, was provided by Melli and Zannetti (1992). Another comprehensive work

\footnotetext{
${ }^{1}$ Mónika Varga

Kaposvár University, Research Group on Process Network Engineering

varga.monika@ke.hu

2 Sándor Balogh

Kaposvár University, Research Group on Process Network Engineering

balogh.sandor@ke.hu

${ }^{3}$ Béla Csukás

Kaposvár University, Research Group on Process Network Engineering

csukas.bela@ke.hu
} 
introduced the attempt to connect geographic information systems with agent-based modeling methodologies to simulate ecological and even social processes dynamically (Gimblett, 2001).

After these relatively early started works, having recognized the need of multiscale problem solving, case-specific models were followed and replaced by the generally applicable modeling frameworks. These general frameworks, such as MIKE SHE (Butts and Graham, 2008), Soil \& Water Assessment Tool (Neitsch et al., 2011), GISHydro (2013), TOPMODEL (USGS, 2005), ANSWERS2000 (Bouraoui et al., 2000) or Watershed Analysis Risk Management Framework (WARMF, 2013) have the ability for the combined consideration of various hydrological processes in watershed scale, built in each other. Majority of these frameworks are studied in the paper of Borah and Bera (2005) in detail, mainly from mathematical point of views.

Hydrologic components of the six most commonly used tools, such as precipitation, potential evapotranspiration, infiltration and surface runoff and streamflow is analysed by Migliaccio and Srivastav (2007), in detail.

Most of these frameworks are still applied for the investigation of different watershed scale processes. According to our review, SWAT (Bosch et al., 2011; Baker and Miller, 2013; Bhuvaneswari et al., 2013) seems to be one of the most known and widely used tool.

Having overviewed the available computational model based systems in the literature; we can say that basically two kinds of tools are available. One of them are the detailed hydrological modeling tools that are difficult to combine with each other and with further models, describing human made processes. Others are the modeling frameworks (like OpenMI or OSM) that are able to combine models, built in different modeling platforms. However, these systems are mainly designed for computer modeling experts and require certain modeling/programming skills.

\subsection{Previous investigations about Lake Balaton area}

Due to the shallow characteristic of Lake Balaton, the vulnerability of its ecosystem, including the whole catchment basin, is high, so it can be considered and managed as a sensitive geographic area. Environmental impacts and human activity has a greater influence, consequently conscious engineering design is required to keep the balance of the ecosystem.

The modeling of this sensitive area has been in the focus of the national research for more than forty years. In the following, without the demand of completeness, we highlight some important issues.

A relatively early volume, prepared by the Institute for Computer Science and Control (Hungarian Academy of Sciences), collected several studies about modeling of Lake Balaton ecosystem (Csáki, 1979). In line with the actual problems on that time, main topic of the volume was the eutrophication, by the modeling of the relevant processes and possibilities, as well as the introduction of Balaton Eutrophication Model (BEM) and its sub-models.

One of the most comprehensive overview from the past decades is the volume of Virág (1998), which covers a range of scientific papers from the hundred years long period of 1896- 1995. On that time it was an overall bibliography with a comprehensive set of data.

Kovács and Clement (2008) dealt with the question of diffuse pollution and investigated the modeling aspects of the related processes, as its came into the limelight again in the first part of the 2000s. Authors highlighted that detailed enough load models are well applicable in this field. Consequently, they reviewed the available models and compared 16 of them in detail, characterized from various aspects (e.g. goal of development, spatial and temporal characteristics, hydrological components, etc.).

"Balaton" entitled thematic issue of the national scientific community was edited by Szlávik (2005). 19 papers of the volume focused on the problems of Lake Balaton, i.e. the question of 
additional water supply, as well as the possible solutions and their impacts on the water quality and on the environment.

Considering the large number of research works, it is a well discovered area, obviously. However, long term climatic, as well as short term extreme meteorological and rapid environmental changes require new perspectives and solutions to maintain the ecologic balance of the area. Furthermore, complex consideration of social needs and evaluations in the course of watershed management is also inevitable.

In our work, we basically focus on the southern catchment basin of the Lake (see Fig 2), while the effects of other catchment basins are taken into consideration with measured data of the inflows from the available time series.

\section{The model building procedure}

Compared with the previously introduced available methods, our Direct Computer Mapping (DCM) based simulation framework offers an intermediate solution with a medium complex, but extendable model. Although, Lake Balaton is one of the mostly studied shallow lake areas, according to our previous experience, the data demand of detailed watershed models (e.g. SWAT) is difficult to satisfy. Accordingly, in our framework we prepared and implemented a medium complex model with simplified (sometimes empirical, heuristic) expressions, considering the available data for the investigated area.

In the next part we describe how the GIS elements were transformed and used in the DCM modeling method to generate the basis of a dynamic simulation model for the investigated watershed. Figure 1 illustrates these steps of the model building procedure, starting from the GIS layers, through the simple graph transformation, until the model identification and validation.

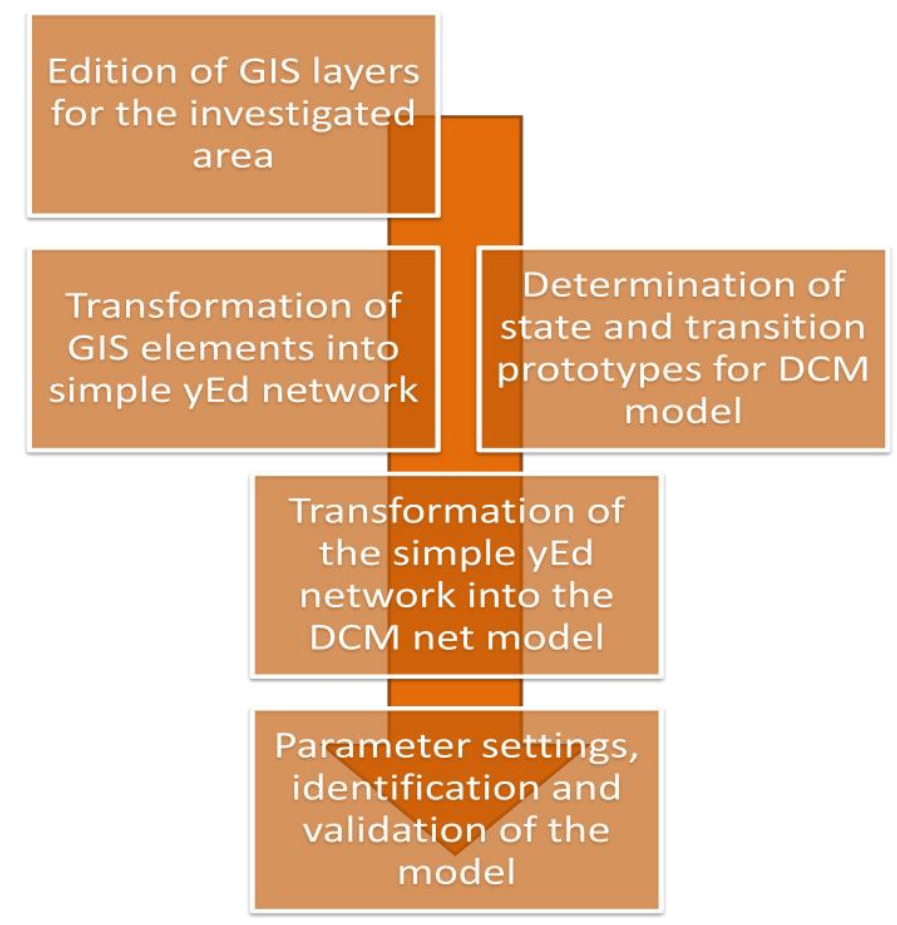

Figure 1. Steps of the model building procedure

\subsection{GIS elements as the basis of dynamic simulation model}

Description of water network in the studied area (left part of Fig. 2.) was started from the corresponding shape files on watercourses, water bodies and sub watersheds, developed by the 
Environmental Protection and Water Management Research Institute (VITUKI). We applied QGIS software (http://qgis.osgeo.org) for the refinement and edition of the original shape files. Serious refinements and actualization had to be made mainly on the shape files, containing the lakes, fishponds, reservoirs and marshes of the watershed.

The sections of water network, transformed into model elements, were the followings:

- waterbody of Lake Balaton, compartmentalized into 20 sub-compartment for the detailed characterization of flows and mixing;

- selected main watercourses of the south-catchment basin, segmented by intermediate small fishponds, lakes; as well as by the boarders of subwatersheds;

- $\quad$ selected lakes, fishponds, reservoirs and marshes in the south-catchment basin.

For the segmentation of area we used the shape files, containing the subwatersheds of the catchment basin.

Nine main watercourses have been selected for deeper investigations in the southern part of the Lake. These nine watercourses were divided into 152 water sections, according to the sub-watersheds and the intermediate smaller waterbodies in the sub-watersheds. These lakes, fishponds or reservoirs were selected according to their size and their importance, considering also the measurement points. Accordingly, 56 small lake compartments were integrated into the model.
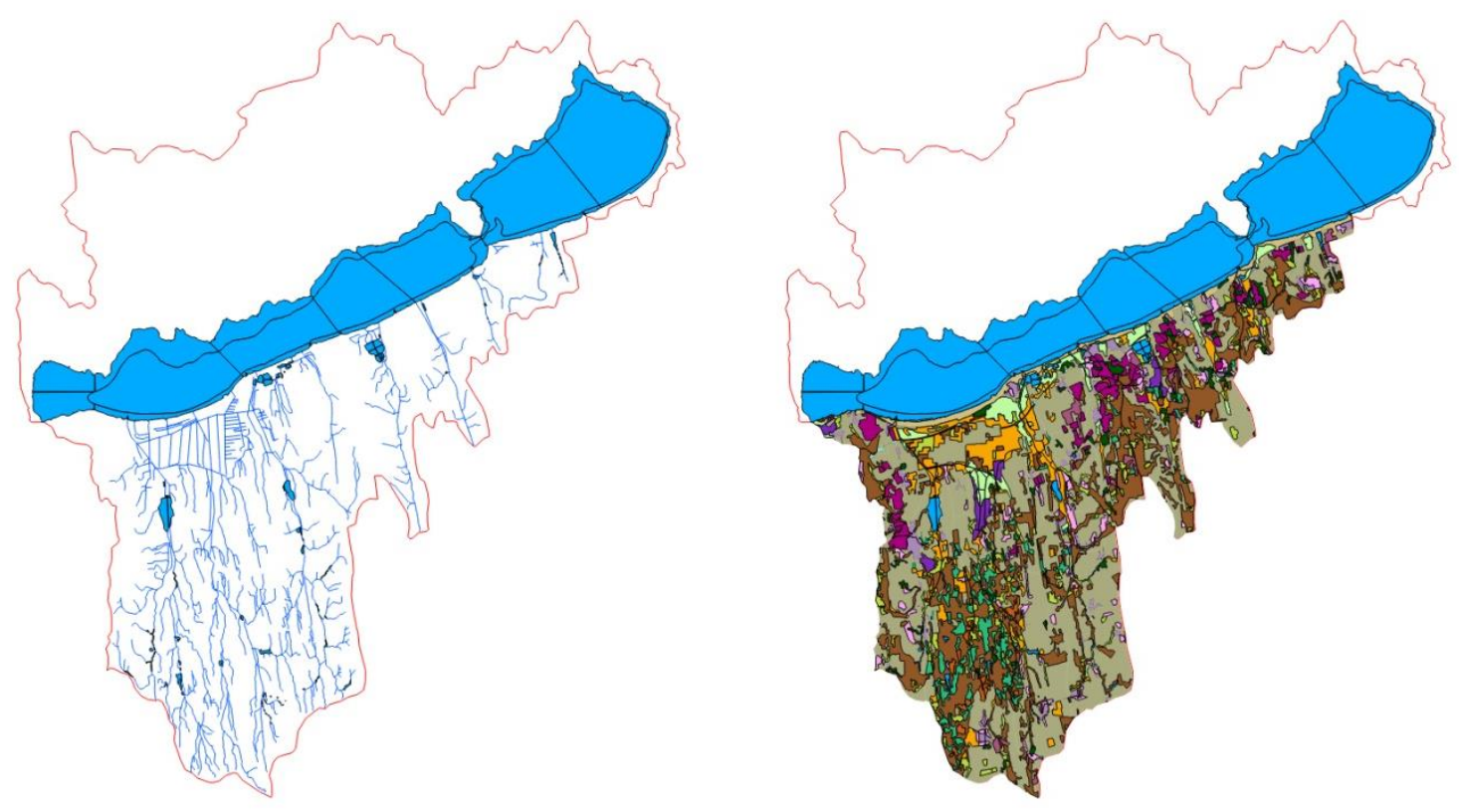

Figure 2. The investigated area: Lake Balaton and its southern watershed. Modeled water courses, lakes and lake compartments (left) and CORINE land patches (right)

Typically, to take into consideration the land use in a computational model, Corine Land Cover database (http://www.fomi.hu/corine/) is used. For the complete and disjoint covering of the whole investigated area, we also applied the vector data of the national data set in 1:100.000 scale (Corine Land Cover 2006 Hungary, right part of Fig. 2.). Data set was created by the Institute of Geodesy, Cartography and Remote Sensing, and it is refined in terms of the changes from 2000 to 2006. Regarding the 1:100.000 scale, minimum mapping unit is 25 ha (in the mapping of 2006 changes is reduced with $5 \mathrm{ha}$ ), as well as the minimum width of linear elements is $100 \mathrm{~m}$. It is noted, that 1:50.000 scale dataset (Büttner et al., 2004) is also available for Hungary, however, the granularity of our model doesn't require this detailedness. Polygons were identified with the general three-level CLC nomenclature.

In the composition of the flow structure, built from the above described water flow segments and from the lakes of the watershed, we applied the Digital Elevation Model (DEM) to determine the 
water network. We described a "From-To" structure, having indicated the continuing water section for each element in the attribute tables of the various layers. It is to be highlighted that in all cases we determined the connecting one and only one water section of the watershed, to which the area provide the water supply, as well as the possible various impurities.

\subsection{Direct Computer Mapping of the investigated problem}

Nowadays complex, multidisciplinary and multiscale models claim for clear and sophisticated coupling of structures and functions. Multiscale, hybrid processes in biosystems and in human-built process networks contain more complex elements and structures, than the theoretically established mathematical constructs. Moreover, the execution of the hybrid, discrete/continuous and optionally multiscale models is a difficult question, because the usual integrators do not tolerate the discrete events, while the usual representation of the continuous processes cannot be embedded into the discrete models conveniently (Meier-Schellersheim et al., 2009). Another challenge is the effective combination of quantitative models with rule-based qualitative knowledge.

Having recognized these difficulties, our approach, called Direct Computer Mapping of process models (Csukás, 1998, Csukás et al, 2011), is based on the principle of "let the computer know the very building elements and the very structure of the process to be modeled". Accordingly, the complex structures and functionalities are mapped onto quite uniform state, transition and connection elements, associated with locally executable programs.

State elements characterize the actual state of the invesstigated process, while transition elements describe the transportations, transformations and rules of the time-driven or event-driven changes in the process. Four kinds of edges are applied to determine the connections between the state and transition elements. Increasing and decreasing connections determine the transport of the additive measures of the state elements; while signaling connections carry the new values of the overwritable signs. An illustrative example for two state and one transition elements with a locally executable program (a flow between water two sections) is explained in Chapter 3, in detail.

So the various process models can be built from the toolbox of these unified building elements.

In parallel with the determination of the state and transition model prototypes, we transformed the various water sections and land patches of the GIS layers into a simple yEd network. In this step, we use the feature of yEd graph editor tool, which allows importing files from spreadsheets. Accordingly, from the "From-To" description of the attribute tables of water network and land patch layers we generated a simple graph.

As a next step, we developed further this simple graph in line with the principles of DCM, with the replacement of simple nodes to state elements (ellipses in Fig 3, corresponds to flow sections, lake compartments, marsh compartments, fishponds and 17 kind of land patches), as well as adding transition elements (rectangles in Fig 3., corresponds to inflows, outflow, flows, mixing, pumps and the patch to water elements) between them.

An example part of the process model, built from this toolbox can be seen in Fig. 3. For the graphical representation of the model elements, as well as to edit the model structure in line with the DCM principles, we use the freely available desktop application of yEd graph editor (http://www.yworks.com). 


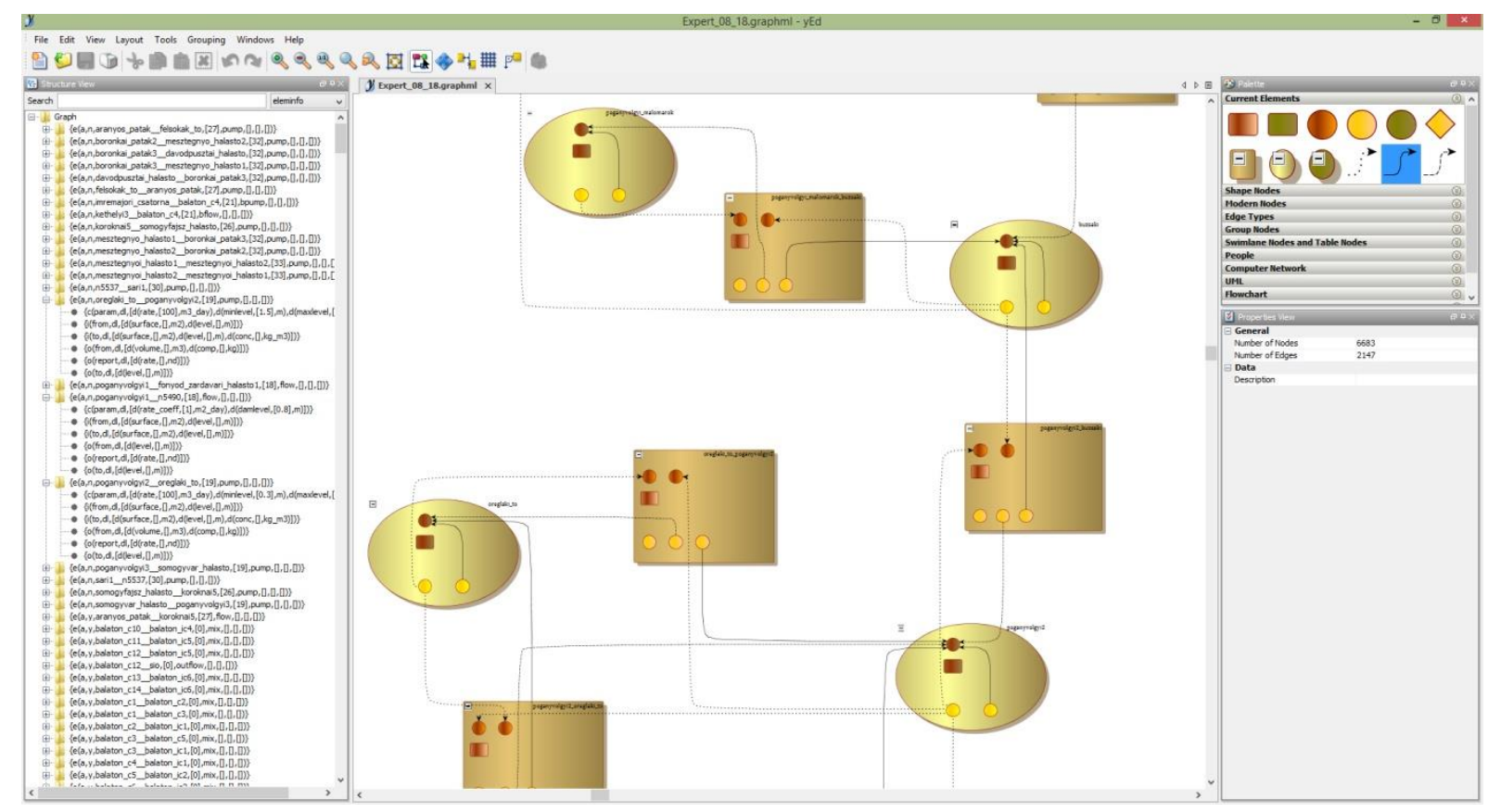

Figure 3. yEd based edition of the structure and parameters

The simulation and the model based problem solving are organized by the execution of these local programs with a general purpose, operating-system-like kernel. Direct Computer Mapping makes possible the unified representation of the natural building blocks of a (model specific conservation law based) balance process and a rule based "informational" process. In this way, the discrete or continuous, as well as quantitative or qualitative functioning can also be interpreted in the same structure.

\section{The implemented hydrological model and the utilized data}

Model building starts with the determination of the general state and transition prototypes, which are contain the formulas to describe the hydrological model. These prototypes were determined as follows. State prototypes, that describe the water networks, are the followings:

- flow sections;

- lake compartments;

- marsh compartments;

- fishponds;

- 17 kinds of land patches (according to CORINE land cover).

Following transition prototypes were determined to describe the water transition between the various water sections and from the various land patches to the connected water elements:

- inflow;

- outflow;

- flows;

- mixing;

- patch to water;

- pump.

All of the state and prototype elements contain their own executable program, as well as the necessary inputs and parameters to calculate the water balance for the investigated area.

In the formulation of the hydrological model, we used a simplified model, started from SWAT. 


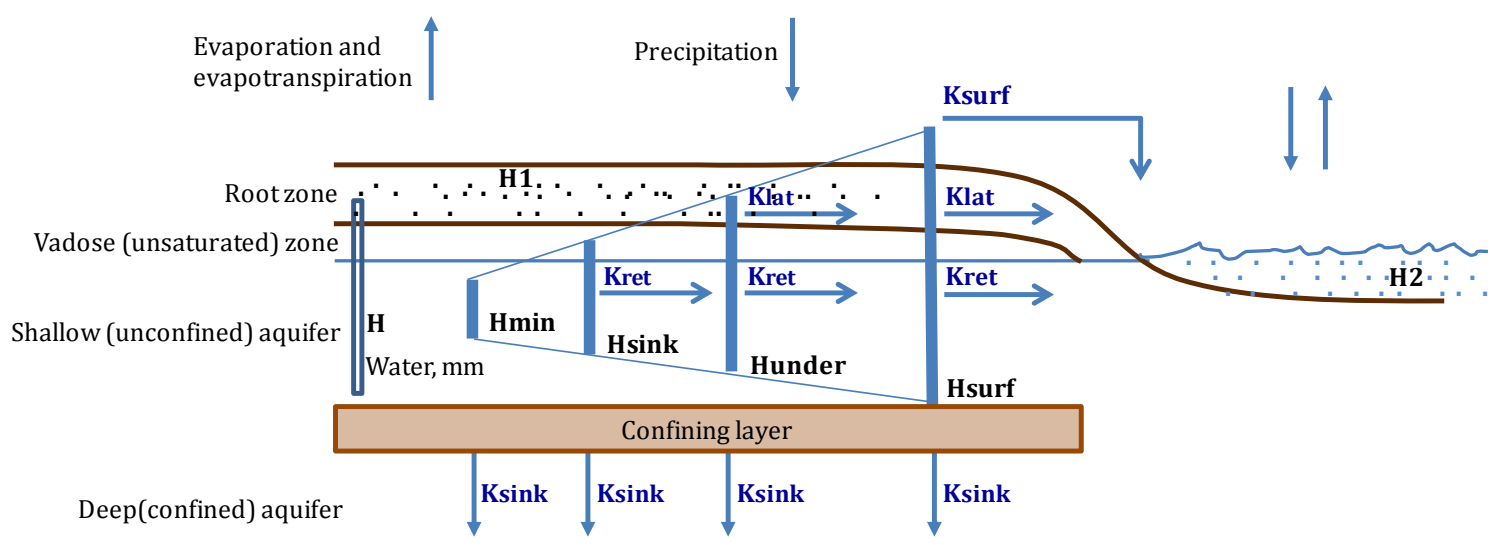

Figure 4. Simplified hydrological model, based on SWAT2009 Theoretical Documentation (http://swat.tamu.edu/media/99192/swat2009-theory.pdf)

According to SWAT, in the simulation of a hydrological model, two kinds of phase (the "land phase" and the "water or routing phase") can be distinguished. In the formulation of land phase processes, we started on the basis of the SWAT land phase description. Accordingly, initial water content of the soil (signed with $\mathrm{H}$ in Fig 4), compared with the limit levels $\left(\mathrm{H}_{\text {min }}, \mathrm{H}_{\text {sink }}, \mathrm{H}_{\text {under }}, \mathrm{H}_{\text {surf }}\right.$ in Fig 5) and with the next section level $\left(\mathrm{H}_{2}\right.$ in Fig 4$)$ determine the various flow coefficients $\left(\mathrm{K}_{\text {sink, }}, \mathrm{K}_{\text {ret, }}\right.$, $\mathrm{K}_{\text {lat }}, \mathrm{K}_{\text {surf }}$ in Fig 4).For the detailed parameterization of water sections, lakes and lake compartments, we get the various data (average depth, length, average width, elevation) from the GIS layers.

Detailed daily meteorological data were available in the calculations for the period 2009-2013. In addition, we use some heuristic expressions for the calculation of evaporation and evapotranspiration on the basis of primary meteorological data.

Keep at the SWAT terminology, for the formulation of water (routing) phase processes, we considered the existing or fictitious dam levels (see Fig. 5), that represent the driving force, determining the amount of flow from a section to the next one.

This simple model can be described by the following Equations:

(1) Rate is $A 1 *(H 1-H k) / D T$,

where

Rate is the amount of water flow from a section to the next one, $\mathrm{m}^{3} /$ dayAl is the surface of the starting water section, $\mathrm{m}^{2}$

$\mathrm{H} 1$ is the level of the starting water section, $\mathrm{m}$

$\mathrm{H}_{\mathrm{k}}$ is the dam level, $\mathrm{m}$

DT is time step of the simulation, actually day

(2) DH2 is Rate $* D T / A 2$,

where

$\mathrm{DH} 2$ is the change of level in the receiving water section, $\mathrm{m}$

DT is time step of the simulation, actually day

$\mathrm{A} 2$ is the surface of the receiving water section, $\mathrm{m} 2$

and

(3) DH1 is $(-1) *$ Rate $* D T / A 1$,

where 
DH1 is the change of level in the starting water section, $m$

DT is time step of the simulation, actually day

$\mathrm{A} 2$ is the surface of the starting water section, $\mathrm{m}^{2}$

This small part of the model is represented by the following program code associated with the respective prototype (written in the declarative Prolog syntax):

$\mathrm{v}(\mathrm{y}, \mathrm{flow},[\mathrm{c}$ (param, dl, [d(rate_coeff, [K], m2_day), d(damlevel, [HK], m) ]) ],

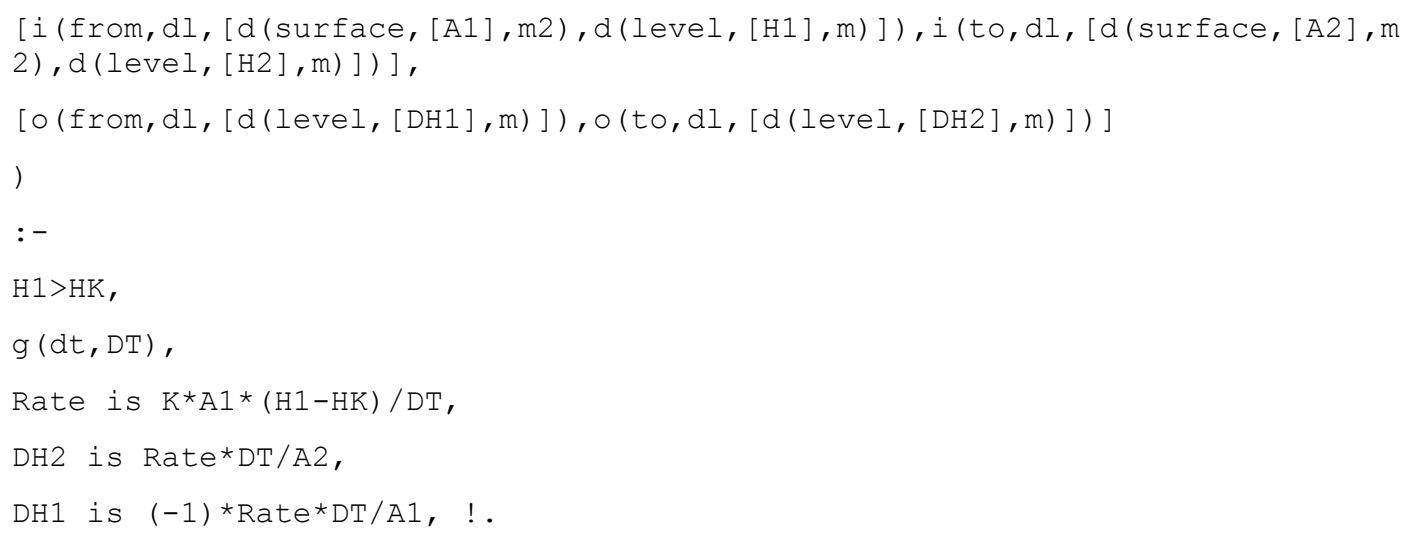

We edit all of the imported GIS elements according to the state prototypes, and extend the network with the actual transition elements, edited according to the transition prototypes.
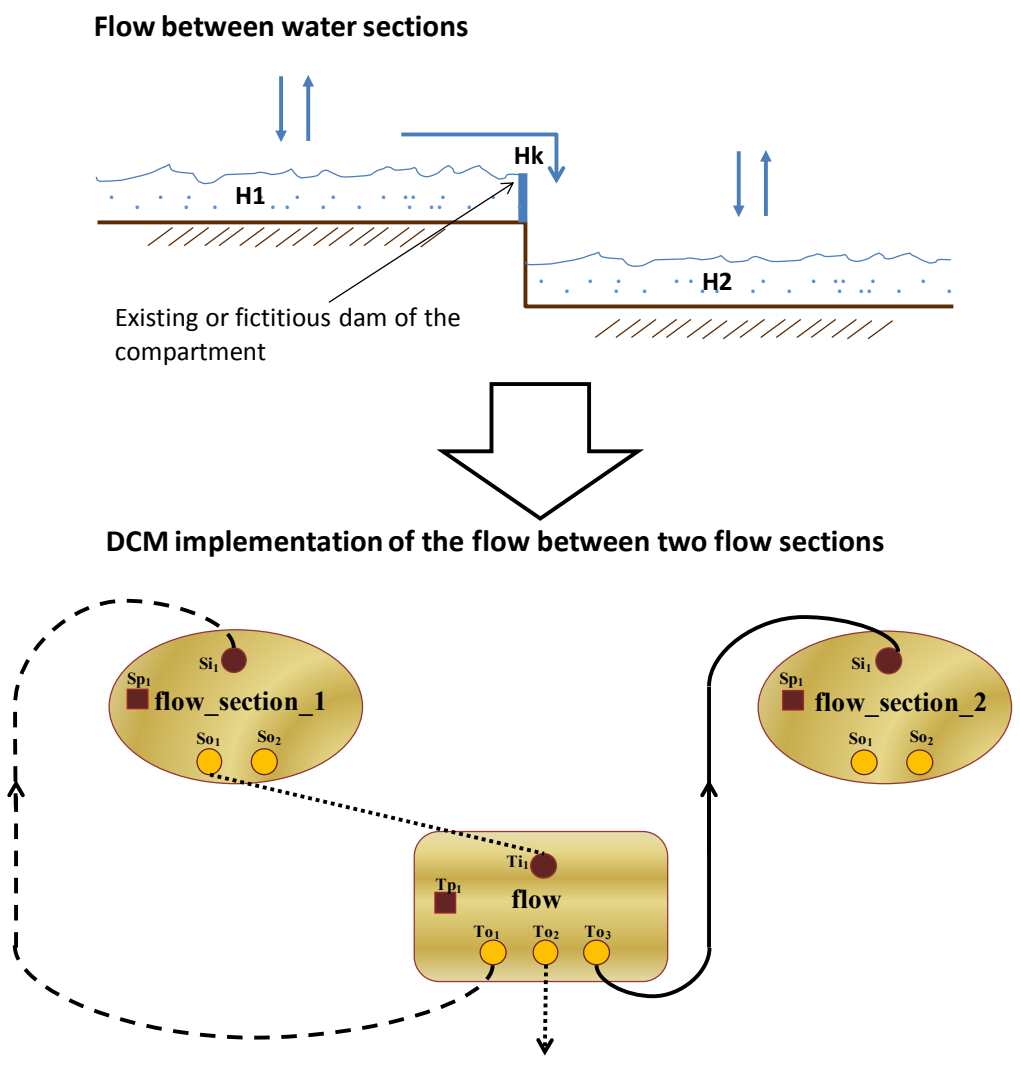

Figure 5. Simplified hydrological model for the water (routing) phase and its DCM implementation

\section{An example case study: Hydrological effects of a possible forestation}


The identified model is able to predict the effects of various meteorological scenarios or various human activities on the hydrology of the watershed. Figure 6 shows an illustration for the result of calculations (red) with the validated model (for one of the largest watercourse, Nyugati-Övcsatorna). Diagram contains also the measured flow rates (monthly average with blue, available unfortunately only for the second year). Accordingly, model calculations show an acceptable agreement with the measured data.

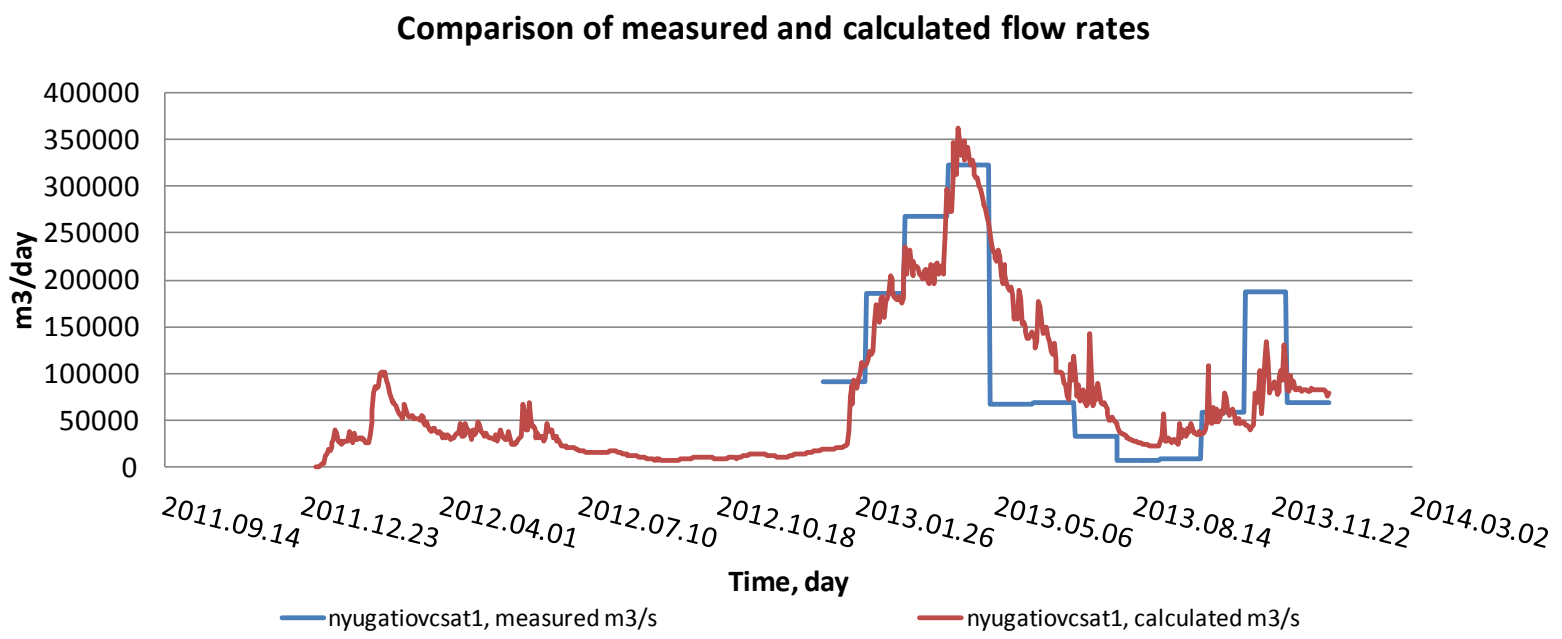

Figure 6. Comparison of measured and calculated data for the inflow Nyugati-Ovcsatorna

With the present state of the identified model, we studied the effects of a possible forestation process on the water balance in the southern watershed. In this hypothetical simulation, we replaced the identified parameters of some meadows and non-cultivated agricultural areas (signed with green in Fig 7) for the parameters of forests (signed with brown in Fig 7). It is noted that we consider the long term result of a hypothetical forestation; however, the methodology could support a longer simulation, accompanying the growing of the forest if the expert could give estimations for the changing plant constants.

It is noted, that although the ratio of the changed area is smaller than the forest areas, the effects on the water balance is observable. According to the calculations, flow rate of the Nyugati-Övcsatorna alone is less with an average value of $8000 \mathrm{~m} 3 /$ day in case of the forestation (Fig. 8 shows this difference). Compared with the original simulation case, difference is $6.7 \%$. It is not significant $\left(\mathrm{R}^{2}=\right.$ 0.996) from statistical point of views, but it illustrates the sensitiveness of the modell well.

The decrease came from the fact, that forest patches have a greater evaporation/evapotranspiration capacity than meadows and non-cultivated lands. Peaks follow the meteorological changes during the year. Figure 9 illustrates the effect of the land use changes on the Lake Balaton level. Considering the shallow characteristics of the Lake, even small changes in meteorological situation (e.g. rainfalls) can cause remarkable fluctuation in the level. Effects of forestation cause slight decrease also in the average level of the Lake. 


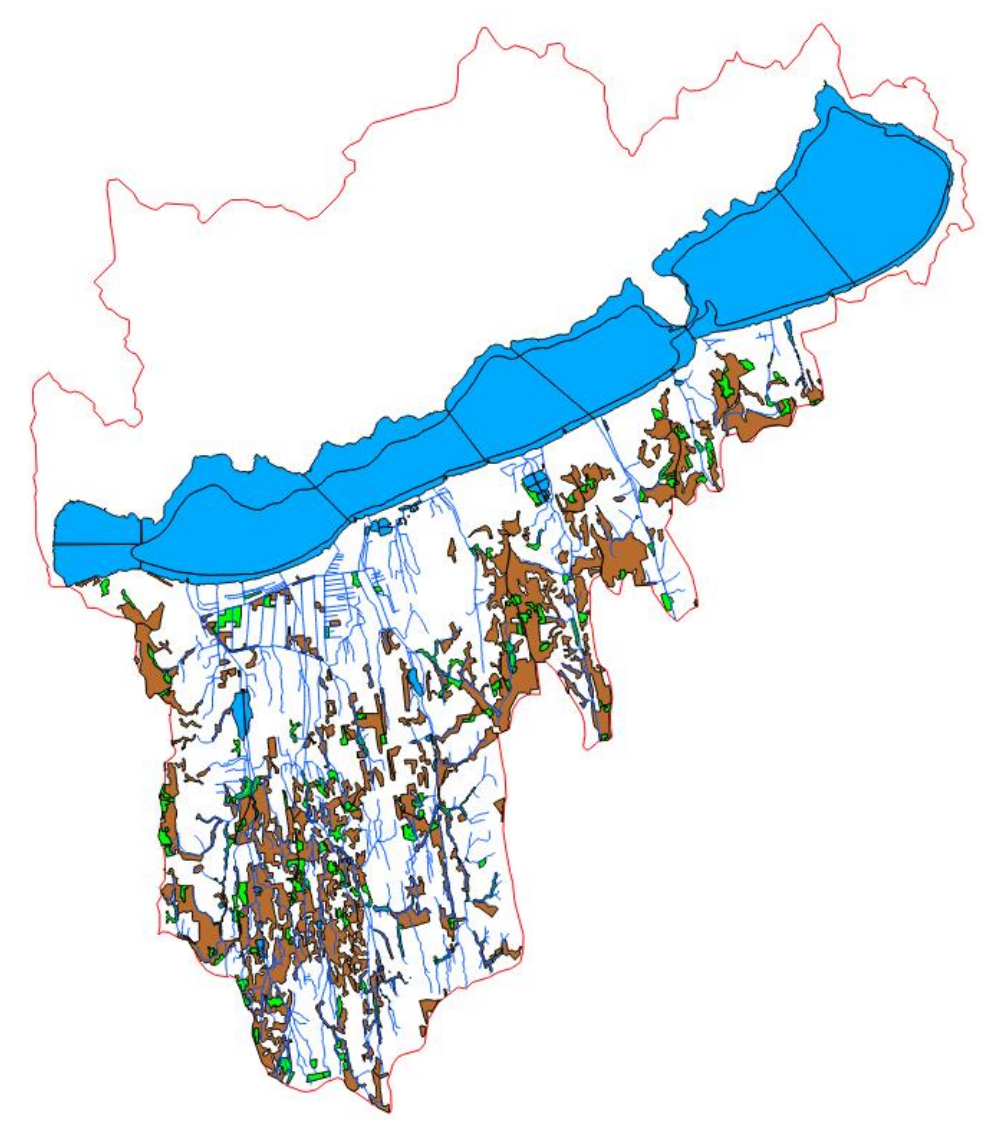

Figure 7. Meadows + non-cultivated agricultural (green), as well as forest areas (brown)

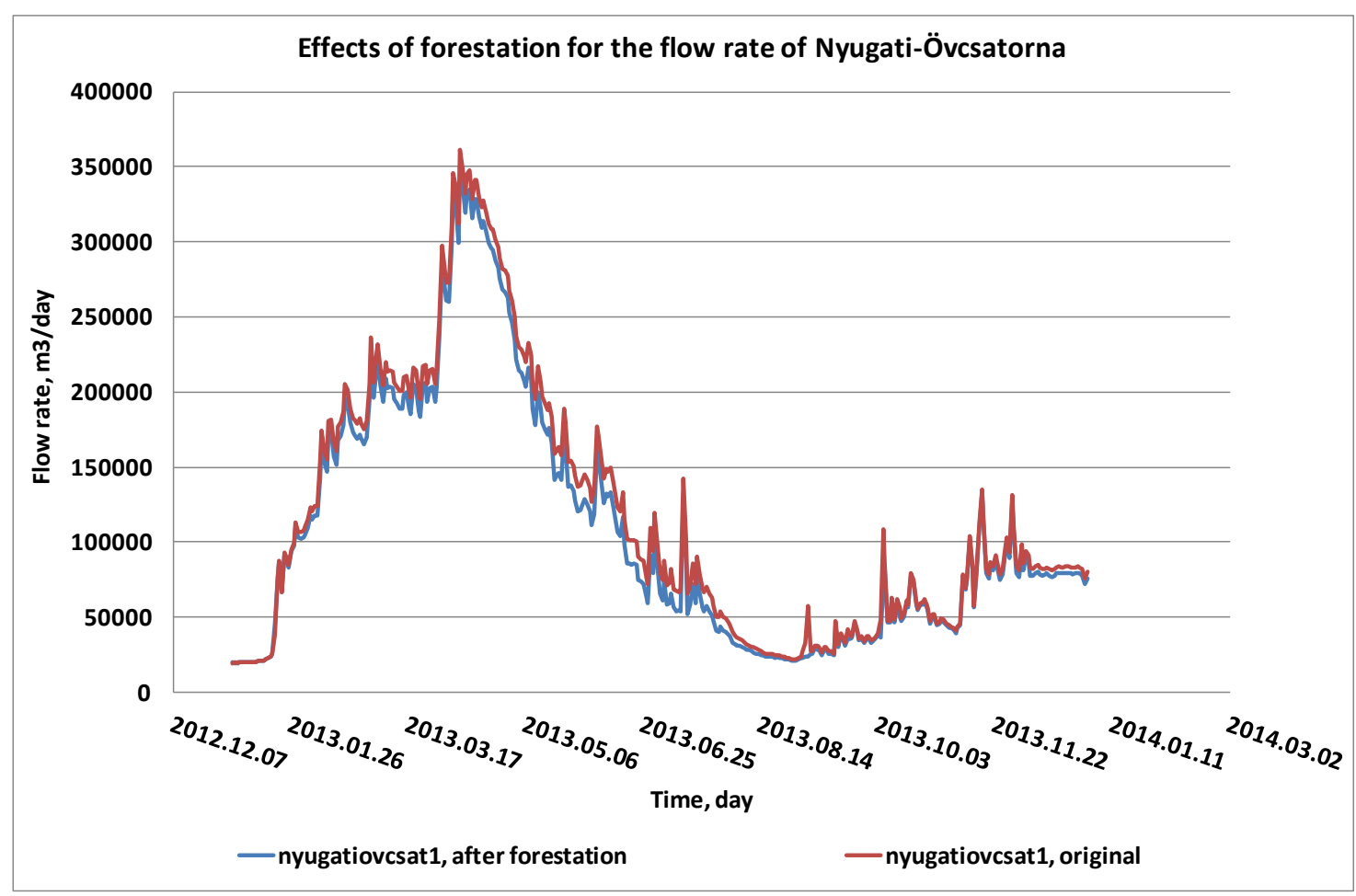

Figure 8. Effects of forestation on a watercourse 
Effects of forestation for the level of Lake Balaton

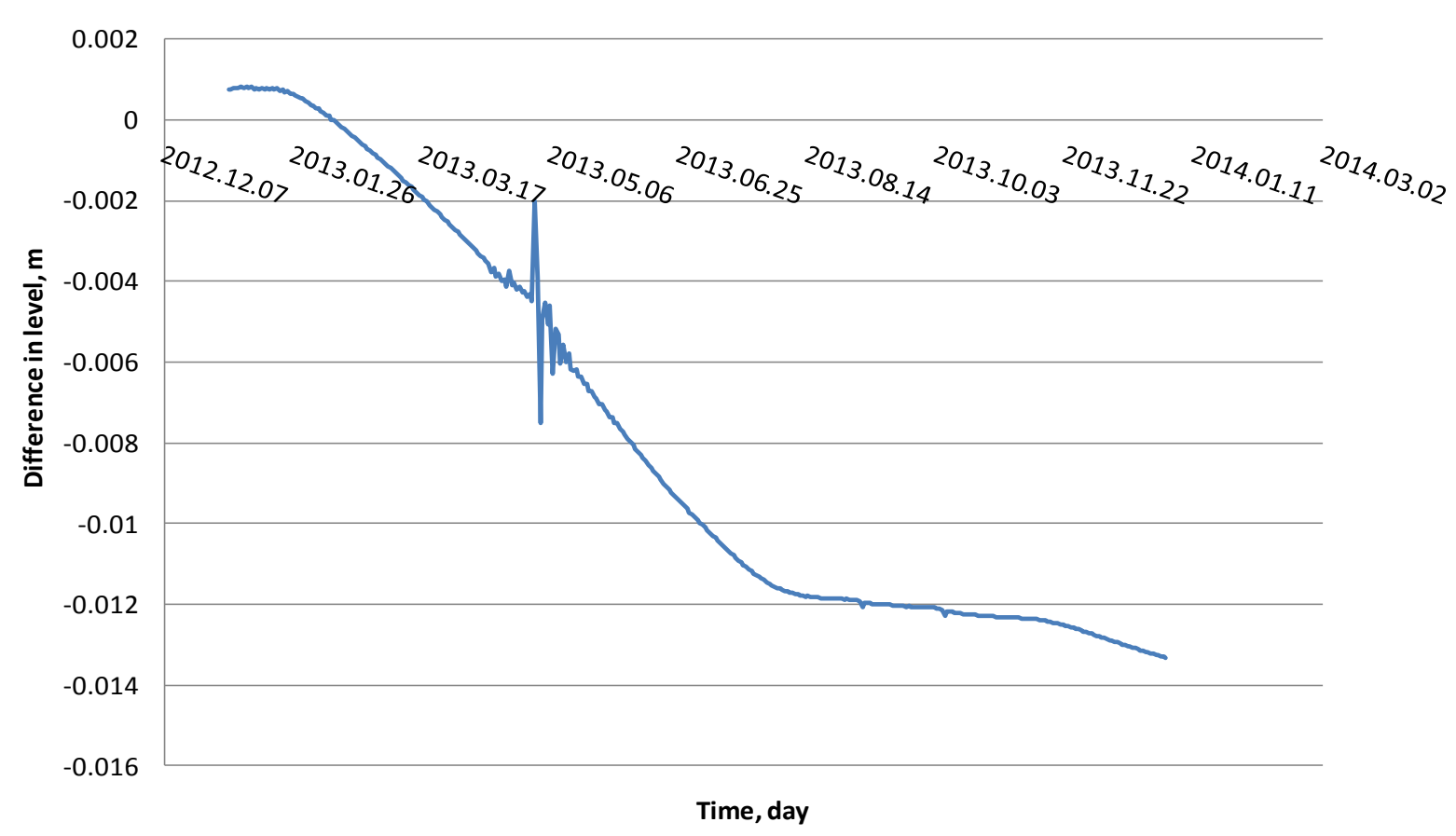

Figure 9. Effects of forestation on the Lake level

\section{Summary}

According to the experiences, we can say that the developed framework is able to integrate the field experts' knowledge (data, relations, empirical knowledge, etc.) for the prediction of land use effects beside different climatic scenarios, flexibly. It is noted, that continuous extension and refinement of the model and of the involved data is necessary, especially through more realistic case studies.

In summary, the main principles of the developed model were the followings:

- The coherence of the model is given by the discretized dynamic network of water flows and storages;

- The completeness is solved by the complete and disjoint covering of the whole area by modeled patches, responsible for the typical parts of natural and human built environment, associated with typical partial interests;

- The complexity of the large scale and long term process is managed by generating and evaluating detailed models only for one representative patch form each class, while the calculation and assessment of the similar patches is solved by simple multiplication rules.

As the core of the developed framework, we applied Direct Computer Mapping to generate dynamic models for simulation based solving of hybrid multi-scale models to support the decision making in rural development. In the generation of model structure, we combined DCM with GIS tools. Expert side availability is ensured by the yEd graph editor for both structural and parametrical edition of the model. Limited user side modification ability is solved by map based web interface.

In line with the developed case studies, we can highlight the followings:

- Prototype land patches linked to the compartments of water network can increase the usability of the distributed measurements for the evaluation of the complex situations (soft sensing).

- Patch model based dynamic simulation of the various past and future scenarios for a sensitive catchment basin (optionally combined with a genetic algorithm) can support decision making in rural development. 
- The method can be developed further for a general tool for the development of large scale, long term sustainable processes (sustainable engineering).

\section{Acknowledgement}

The research was funded by the TÁMOP-4.2.2.A-11/1/KONV-2012-0038 and TÉT_12_CN-12012-0041 projects.

\section{References}

Baker, T.J., Miller, S.N. 2013. Using the Soil and Water Assessment Tool (SWAT) to assess land use impact on water resources in an East African watershed. Journal of Hydrology. 486: 100-111. doi:10.1016/j.jhydrol.2013.01.041

Bhuvaneswari, K., Geethalakshmi, V., Lakshmanan, A., Srinivasan, R., Sekhar, N.U. 2013. The Impact of El Niño/Southern Oscillation on Hydrology and Rice Productivity in the Cauvery Basin, India: Application of the Soil and Water Assessment Tool. Weather and Climate Extremes. 2: 39-47. doi:10.1016/j.wace.2013.10.003

Borah, D.K., Bera, M. (2003) Watershed-scale hydrologic and nonpoint-source pollution models: Review of mathematical bases. Transactions of the American Society of Agricultural Engineers. 46(6): 1553-1566. ISSN 0001-2351. doi: $10.13031 / 2013.15644$

Bosch, N.S., Allan, J.D., Dolan, D.M., Han, H., Richards, R.P.. 2011. Application of the Soil and Water Assessment Tool for six watersheds of Lake Erie: Model parameterization and calibration. Journal of Great Lakes Research. 37(2): 263-271. doi:10.1016/j.jglr.2011.03.004

Bouraoui, F., Dillaha, T. 2000. ANSWERS-2000: Nonpoint-source nutrient planning model. J. Environ. Eng. 126(11): 1045-1055. doi:10.1061/(asce)0733-9372(2000)126:11(1045)

Büttner, G., G. Maucha, M. Bíró, B. Kosztra, R. Pataki, O. Petrik. 2004. National Lanc Cover database at scale 1:50000 in Hungary. EARSeL eProceedings 3, 3/2004, 323-330.

Butts, M.B., Graham, D.N. 2008. Evolution of an integrated surface water-groundwater hydrological modelling system, 7 pp. In: IAHR International Groundwater Symposium 2008. Flow and Transport in Heterogeneous Subsurface Formations: Theory, Modelling \& Applications. Istanbul, Turkey, June 18-20, 2008. Retrieved February 13, 2014, from http://feflow.info/fileadmin/FEFLOW/content tagung/TagungsCD/papers/30.pdf

Csáki, P. (ed.) 1979. A Balatoni ökoszisztéma modellezése. Tanulmányok 93/1979, MTA Számítástechnikai és Automatizálási Kutató Intézet, Budapest, in Hungarian

Csukás, B. 1998. Simulation by Direct Mapping of the Structural Models onto Executable Programs, AIChE Annual Meeteng, Miami, Paper 239/9.

Csukas, B., Varga, M., Balogh, S. 2011. Direct Computer Mapping of Executable Multiscale Hybrid Process Architectures. In: Proceedings of Summer Simulation Multiconference'2011, Den Haag. Hollandia, 2011.06.262011.06.29. pp. 87-95.(ISBN:1-56555-345-4)

Duckstein, L., Gershon, M., McAniff, R. 1982. Model selection in multiobjective decision making for river basin planning. Advances in Water Resources. 5(3): 178-184. doi:10.1016/0309-1708(82)90040-9

Gimblett H.R. (ed.) 2001. Integrating Geographic Information Systems and Agent-Based Modeling Techniques for Simulating Social and Ecological Processes, Oxford University Press.

GISHydro, http://www.gishydro.eng.umd.edu/, Retrieved 12. December 2013.

Knapen, R., Janssen, S., Roosenschoon, O., Verweij, P., de Winter, W., Uiterwijk, M. 2013. Evaluating OpenMI as a model integration platform across disciplines. Environmental Modelling \& Software. 39: $274-282$.

doi:10.1016/j.envsoft.2012.06.011

Kovács, Á., Clement, A. 2008. Diffúz szennyezés modellezése vízgyűjtő léptékben: esettanulmány tapasztalatok. Manuscript, BME VKKT, Retrieved in January 10. 2013 from http://www.vkkt.bme.hu/feltoltesek/2011/01/non_point2.doc

Meier-Schellersheim, M., Fraser, I.D.C., Klauschen, F. 2009. Multiscale modeling for biologists. In: Wiley Interdisciplinary Reviews: Systems Biology and Medicine, 1(1): 4-14 doi: 10.1002/wsbm.33

Melli, P., Zannetti, P. (eds.) 1992. Environmental Modeling. Computational Mechanics Publications, Elsevier Applied Science, Glasgow 
Migliaccio, K.W., Srivastava, P. 2007. Hydrologic Components of Watershed-Scale Models. Transactions of the ASABE. American Society of Agricultural and Biological Engineers. 50(5): 1695-1703. ISSN 0001-2351 doi: $\underline{10.13031 / 2013.23955}$

Neitsch, S.L., Arnold, J.G., Kiniry, J.R., Williams, J.R. 2011. Soil \& Water Assessment Tool. Theoretical Documentation Version 2009. Texas Water Resources Institute Technical Report No. 406, Texas A\&M University System, College Station, Texas

Soil and Water Assessment Tool. 2009. Theoretical Documentation, Version 2009. Retrieved in May 08, 2014 from http://swat.tamu.edu/media/99192/swat2009-theory.pdf

Szlávik, L. ed. 2005. A Balaton. Vízügyi Közlemények (special issue). Környezetvédelmi és Vízgazdálkodási Kutatóintézet Kht., Budapest, in Hungarian

TOPMODEL software http://www.es.lancs.ac.uk/hfdg/freeware/hfdg_freeware top.htm, Retrieved 7. January 2014.

Virág, Á. (ed.) 1998. A Balaton múltja és jelene. Egri Nyomda Kft, Eger, in Hungarian

WARMF, http://www.epa.gov/athens/wwqtsc/html/warmf.html, Retrieved 20. December, 2013

Zagona, E.A., Fulp, T.J., Shane, R., Magee, T., Goranflo, H.M. 2001. RiverWare: a generalized tool for complex reservoir system modelling. Journal of the American Water Resources Association. 7(4): 913-929.

doi: 10.1111/j.1752-1688.2001.tb05522.x 